\title{
AG275, AG294 and AG274 antibodies recognize the hen egg-white lysozyme by ELISA
}

Benjamin Adomako ${ }^{1}$, Tess Arbez ${ }^{1}$, Luca Baltazar ${ }^{1}$, Jade Berlincourt ${ }^{1}$, Marc Bobillier ${ }^{1}$, Diana Boeva ${ }^{1}$, Agnès Bury ${ }^{1}$, Alexis Calomeni ${ }^{1}$, Hania Farhat ${ }^{1}$, Eva Garrido ${ }^{1}$, Hugo Gillet ${ }^{1}$, Tasnim Khadam-Al-Jame ${ }^{1}$, Patricia Lopez ${ }^{1}$, Maria Lung ${ }^{1}$, Anja Maag ${ }^{1}$, Vincent Mendes Ferreira $^{1}$, Garance Michel ${ }^{1}$, Marin Ollagnon ${ }^{1}$, Yekaterina Prutyanova ${ }^{1}$, Julien Schär ${ }^{1}$, Emma Siebenmann ${ }^{1}$, Bethania Tamrat ${ }^{1}$, Mathieu Vigneau $^{1}$, Maxime Zholdokov ${ }^{1}$, Philippe Hammel ${ }^{2}$, Stéphane Durual ${ }^{3}$, Cyril Guilhen ${ }^{1}$

${ }^{1}$ Bachelor in Biomedical Sciences, Faculty of Medicine, University of Geneva, 1 rue Michel Servet, CH-1211, Geneva, Switzerland ${ }^{2}$ Geneva Antibody Facility, Faculty of Medicine, University of Geneva, 1 rue Michel Servet, CH-1211, Geneva, Switzerland ${ }^{3}$ University Clinics of Dental Medicine, University of Geneva, 1 rue Michel Servet, CH-1211, Geneva, Switzerland

\begin{abstract}
The recombinant antibodies AG275, AG294 and AG274 detect the hen egg-white lysozyme by ELISA.
\end{abstract}

\section{Introduction}

Lysozyme is an antibacterial enzyme widely distributed in vertebrates, invertebrates, plants, and microbes. It is also found in a large variety of animal secretions and tissues such as saliva, mucus, or avian eggs, and it is secreted by polymorphonuclear leukocytes among other cells (Mason and Taylor, 1975). Lysozyme hydrolyzes the 1,4-betalinkages between N-acetylmuramic acid and Nacetylglucosamine in the peptidoglycan of Gram-positive bacteria (Chipman and Sharon, 1969). Three recombinant antibodies (AG275, AG294 and AG274) detect the hen egg-white lysozyme (HEWL) (Uniprot P00698) by ELISA. Two other tested antibodies (AE913 and AE915) did not.

\section{Materials \& Methods}

Antibodies: ABCD_AE913, ABCD_AE915, ABCD_AG274, ABCD_AG275 and ABCD_AG294 antibodies (ABCD nomenclature, https://web.expasy.org/ abcd/) were produced by the Geneva Antibody Facility (http:/www.unige.ch/medecine/antibodies/) as miniantibodies with the antigen-binding portion fused to a rabbit IgG Fc. The synthesized scFv sequences (GeneArt, Invitrogen) correspond to the sequences of the variable regions joined by a peptide linker (GGGGS) ${ }_{3}$ (see Table 1 for clone names and references). HEK293 suspension cells (growing in FreeStyle ${ }^{\mathrm{TM}} 293$ Expression Medium, Gibco 12338) were transiently transfected with the vector coding for the scFv-Fc of each antibody. Supernatants (see Table 1 for individual yields) were collected after 4 days.

Table 1: Clone number, reference and production yields for the antibodies used in this study.

\begin{tabular}{|l|c|c|c|}
\hline ABCD & Clone & Reference & Yield (mg/L) \\
\hline AE913 & L2,5 & \multirow{2}{*}{ Davies et al ., 1995 } & 100 \\
\cline { 1 - 1 } AE915 & L1 & & 10 \\
\hline AG274 & D44.1 & Braden et al ., 1994 & 5 \\
\hline AG275 & HyHEL-63 & Li et al ., 2000 & 70 \\
\hline AG294 & D1.3 & Holmes et al ., 1998 & 80 \\
\hline
\end{tabular}

Protocol: The whole procedure was carried out at room temperature. HEWL (5 $\mu \mathrm{g} / \mathrm{mL}$; Sigma L6876) was incubated in high protein-binding capacity 96-well plates (50 $\mu \mathrm{l} /$ well) (Thermo Fisher Scientific 44-2404) for 30 minutes. The support was blocked 20 minutes in PBS containing 4\% (w/v) BSA. Each well was rinsed three times with $100 \mu \mathrm{L}$ of washing buffer (PBS $+0.1 \%(\mathrm{w} / \mathrm{v})$ BSA $+0.05 \%(\mathrm{w} / \mathrm{v})$ Tween 20$)$, then incubated for 30 minutes with $50 \mu \mathrm{l}$ of antibody-containing supernatant diluted in washing buffer as indicated (Fig. 1). After rinsing 3 times (100 $\mu \mathrm{l}$ washing buffer), wells were incubated with horseradish peroxidase-coupled goat antirabbit IgG (Sigma A8275, dilution 1:1000, $50 \mu$ l per well) for $30 \mathrm{~min}$. After 5 rinses, Tetramethylbenzidine (TMB) substrate (Sigma T5569) was added (50 $\mu$ l per well). The reaction was stopped by the addition of $25 \mu \mathrm{l}$ of $2 \mathrm{M}$ $\mathrm{H}_{2} \mathrm{SO}_{4}$. The absorbance (OD) was measured at $450 \mathrm{~nm}$.

\section{Results}

Antibodies AG275, AG294 and AG274 bound in a concentration-dependent manner to the HEWL, but not to the BSA negative control (Fig. 1). AE913 and AE915 did not recognize the HEWL by ELISA.

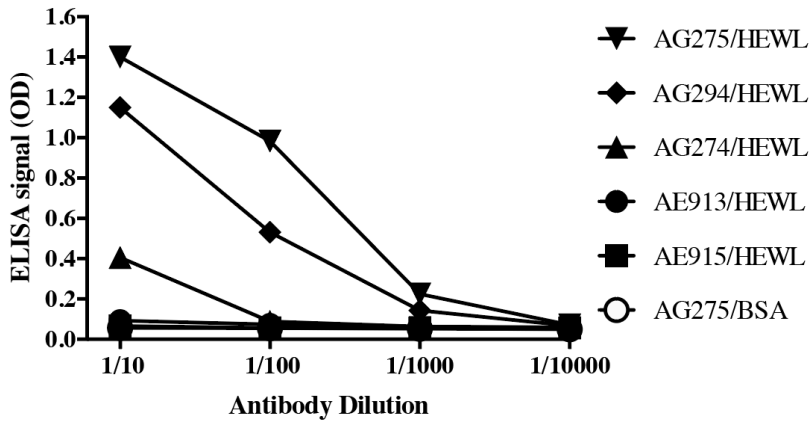

Fig. 1. AG275, AG294 and AG274 bound specifically to the hen eggwhite lysozyme (HEWL), but not to the BSA control (shown only for AG275; the other background curves were superimposed), as detected by ELISA. 


\section{References}

Braden BC, Souchon H, Eiselé J-L, et al. Threedimensional structures of the free and the antigencomplexed Fab from monoclonal anti-lysozyme antibody D44.1. J Mol Biol. 1994; 243(4):767-81. PMID: 7966295.

Chipman DM, Sharon N. Mechanism of lysozyme action. Science. 1969; 165(3892):454-65. PMID: 4893486.

Davies EL, Smith JS, Birkett CR, Manser JM, AndersonDear DV, Young JR. Selection of specific phage-display antibodies using libraries derived from chicken immunoglobulin genes. J Immunol Methods. 1995; 186(1):125-35. PMID: 7561141.
Holmes MA, Buss TN, Foote J. Conformational correction mechanisms aiding antigen recognition by a humanized antibody. J Exp Med. 1998; 187(4):479-85. PMID: 9463398.

Li Y, Li H, Smith-Gill SJ, Mariuzza RA. Threedimensional structures of the free and antigen-bound fab from monoclonal antilysozyme antibody HyHEL-63. Biochemistry. 2000; 39(21):6296-309. PMID: 10828942.

Mason DY, Taylor CR. The distribution of muramidase (lysozyme) in human tissues. J Clin Pathol. 1975; 28(2):124-32. PMID: 1092717.

\section{Conflict of interest}

The authors declare no conflict of interest. 